\title{
Effect of Supplementary Cementitious Material and Fine Recycled Aggregates on Shrinkage Properties of Self-Compacting Microconcrete
}

\author{
Miren Etxeberria and B.T. Purandhar Reddy
}

Department of Civil and Environmental Engineering (DECA), Universitat Politècnica de CatalunyaBarcelonaTECH, Campus Nord UPC, 08034-Barcelona, Spain, miren.etxeberria@upc.edu

\begin{abstract}
An increase in the population has led to the progressive construction of infrastructures and buildings. This causes severe environmental problems, firstly high emissions of CO2 are caused in cement production; secondly, a high volume of construction and demolition waste is landfilled and thirdly, it is necessary to look for new, no natural resources for the production of construction materials. The objective of this work is to analyse the influence of fine recycled aggregates and high volumes offly ash in the properties of high-performance self-compacting (SC) microconcrete. The experimental work presented in this paper was carried out in two phases. In phase 1, SC-microconcrete were produced with 100\% of Portland cement, and natural sand was replaced by both mixed and ceramics recycled aggregates in $30 \%$ and $50 \%$. In phase 2, SC-microconcretes were produced with the replacement of $50 \%$ of Portland cement by fly ash, and natural sand was replaced by both mixed and ceramics recycled aggregates in $30 \%$ and $50 \%$. In each phase, the drying and autogenous shrinkage of all mortars was measured via their storage in a climate chamber after 24 hours of casting and the determining of properties during 90 days. In order to assess the influence of the shrinkage effect on the mechanical properties, the prismatic samples were also stored in a climatic chamber, and the compressive strength at several ages was determined in all of the SC mixtures. The results showed that the microconcretes produced employing mixed and ceramic fine aggregates achieved higher compressive strength and lower autogenous shrinkage. Although the $C-N$ achieved the lowest drying shrinkage, the mixtures with $30 \%$ of CRA and MRA were found to have similar values. The employment of the CRA aggregates improved the drying shrinkage and compressive strength of the C-FA-N mixture.
\end{abstract}

Keywords: Self-Compacting Microconcrete, Fly Ash, Fine Recycled Aggregates, Shrinkage.

\section{Introduction}

The portland cement (PC) industry is one of the major contributor to $\mathrm{CO} 2$ emissions. In recent years, Fly Ash (FA) has been widely used as supplementary cement material in replacement of part of PC in concrete construction. In addition, the mixtures employing FA require low water content in order to achieve good workability (Abdalhmid, Ashour, and Sheehan, 2019; DuranHerrera, De-León-Esquivel, Bentz, and Valdez-Tamez, 2019; Kristiawan and Aditya, 2015; Matos, Foiato, and Prudêncio, 2019). Dinakar et al. (Dinakar, Kartik Reddy, and Sharma, 2013) described that about $30 \%-50 \%$ of FA content was ideal for the production of self-compacting concrete (SCC). It was determined that the replacement of $50 \mathrm{wt} \% \%$ of PC by siliceous fly ash resulted in a low contribution to the hydration at early ages (up to 2 days of age). Between 12 $\mathrm{h}$ and 2 days after casting, the hydration is influenced by the so called "filler effect" of FA. Between 2 and 7 days, the fly ash reaction was detected by measuring the increase in chemical shrinkage, bound water and reduced portlandite contents (Deschner et al., 2012). According to Matos et al. (Matos et al., 2019), the compressive strength gains in SCC with FA were significant up to 180 days. According to certain researchers (Abdalhmid et al., 2019; DuranHerrera et al., 2019; Kristiawan and Aditya, 2015) a higher cement replacement of FA tends to 
decrease both drying and autogenous shrinkage. According to Altoubat et al. (Altoubat, Junaid, Leblouba, and Badran, 2017), the high strength SCC tested employing high degree of restraint (ASTMrings) showed that cement replacement of up to $35 \%$ of FA does not compromise the cracking resistance of the mix. The free shrinkage and thus the shrinkage potential of the SCC mixes decreases. It is also known that the employment of high absorption capacity recycled aggregates (RA) are able to reduce the autogenous shrinkage of high performance RA concrete (Etxeberria, Miren, Gonzalez-Corominas, 2018; Suzuki, Seddik Meddah, and Sato, 2009). The drying shrinkage of concrete increases when RA are employed. However, Behera et al. (Behera, Minocha, and Bhattacharyya, 2019) determined that in SCC concrete produced with fine RA and the ternary blend binder was more effective in controlling the shrinkage strain of concrete. Internal Curing can reduce autogenous shrinkage and improve concrete quality. Internal curing is necessary for designing HPC, and conventional concrete with low water-cement ratio, when RA have been employed (Al Saffar, Al Saad, and Tayeh, 2019).

In this research work the influence of the FA, supplementary cementitious material, as well as the employment of mixed and ceramic recycled aggregates (MRA and CRA, respectively) on the shrinkage and compressive strength of SC-microconcrete exposed to drying and sealing curing condition were analysed.

\section{Materials}

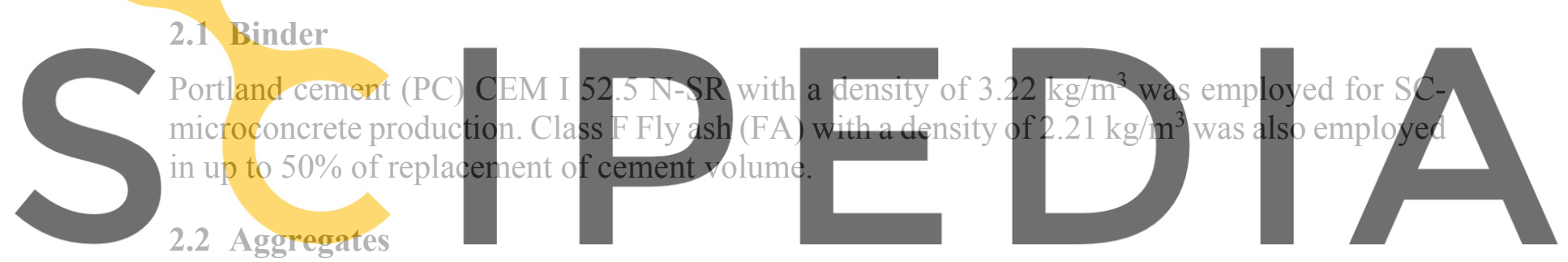

\subsection{Aggregates}

\section{Natural Silica sand (NA) with a fraction of $0 / 4 \mathrm{~mm}$ was employed for SC-microconcrete for free at https/Nww scipedia.com to downlond the version with $94 \mathrm{t}$ the 3 watermark $2.43 \%$, respectively.}

Fine MRA and CRA aggregates were employed in replacement of up to $50 \%$ of natural aggregates. The MRA aggregates were composed of approximately, $70 \%$ ceramic, $20 \%$ of concrete, $9.4 \%$ of raw aggregates, $0.5 \%$ of gypsum, and $0.1 \%$ of other components. The composition of the CRA aggregates was 100\% ceramic material. The fraction of both RA was $0 / 4 \mathrm{~mm}$, but their grading distribution was coarser than that of the NA aggregates, however they proved to have more particles finer than $63 \mu \mathrm{m}$, which were $2 \%, 11 \%$ and $14.5 \%$ in the NA, MRA and CRA aggregates, respectively. The dry density (determined following UNE-EN 1097-6) of MRA and CRA were $1.92 \mathrm{~kg} / \mathrm{dm}^{3}$ and $1.97 \mathrm{~kg} / \mathrm{dm}^{3}$, respectively. The water absorption capacity of MRA and CRA was determined following UNE-EN 1097-6 specification proved to be $15.5 \%$ and $14.0 \%$, respectively. The absorption capacity which was determined following the NY703-19 specification was $15.4 \%$ and $12.2 \%$, respectively. Those last values were employed for concrete mixture design.

A superplasticizer based on PAE polymer technology was employed in all mixtures. 


\section{Mix Design and Production Process}

Two series of the SC-microconcrete production were carried out, with five different mixtures produced in each of the series, see Table 1 .

In Series 1 all the mixtures were produced employing 100\% PC. In series 2, the same volume of binder employed in series 1 was used, but the binder was composed of $50 \%$ of PC and $50 \%$ of FA. In both series five SC-micrococrete mixtures were produced, one with $100 \%$ of natural sand and the other four mixtures employing MRA and CRA in 30\% and 50\%. In all mixtures the effective water-cement ratio of 0.27 was maintained. The RA was employed in saturated conditions (the value determined according to NY 703-19 standard).

A planetary mixer BE-20, in a low -medium speed was employed for SC-microconcrete production. The same production process was applied for all the SC-microconcretes. Firstly PC, FA and the $95 \%$ of effective water amount were mixed; secondly NA, the pre-saturated MRA/CRA were added to the mixer and mixing continued at a low speed. Thirdly, the chemical admixture was added together with the 5\% of effective water amount. Finally, all the accumulated material was removed manually from the bottom and mixing continued for a few minutes. On finalizing the SC-microconcrete production, a slump flow test was performed according to EFNARC (Ankush, Rajeev, and Koshta, 2014; European Federation for Specialist Construction Chemicals and Concrete Systems (EFNARC), 2005). The spread diameter, D, of all the mixtures kept within the range of $250 \pm 10 \mathrm{~mm}$ (see Table 3). The flow of the mixtures was adequate, and did not present bleeding and segregation. In series 2, the SC-microconcrete

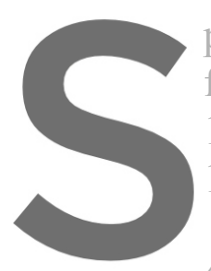
produced employing fluidity. While followi $12.2 \%$ we believe it to $14 \%$. 4 Test Procedure
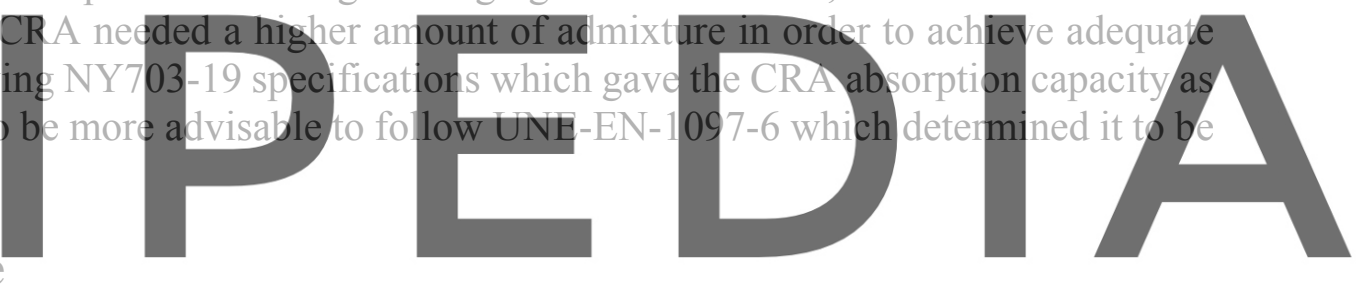

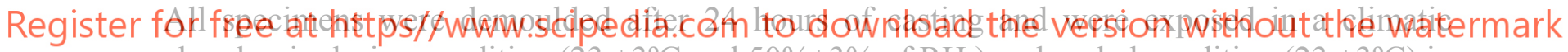
chamber in drying condition $\left(23 \pm 3^{\circ} \mathrm{C}\right.$ and $50 \% \pm 3 \%$ of $\left.\mathrm{RH}\right)$ and sealed condition $\left(23 \pm 3^{\circ} \mathrm{C}\right)$ in order to determine the drying and autogenous shrinkage after 24 hours of casting. The compressive strength of samples exposed to those curing condition was also determined.

\subsection{Shrinkage (Autogenous-Sealed and Drying)}

The shrinkage of the SC-microconcrete was determined following UNE-EN 12617-4 specifications. Six $25 \times 25 \times 287 \mathrm{~mm}$ specimens were produced for each type of SCmicroconcrete. After casting, they were covered with plastic film, in order to avoid water evaporation, and place in the humidity room for 24 hours. After 24 hours of casting, all the specimens were demoulded. Half of the specimens were employed for autogenous (sealed) shrinkage determination and the other half for drying shrinkage (both shrinkage measurements were determined 24 hours after casting). A digital length comparator was employed for length measurements at different ages. According to their autogenous shrinkage values, the specimens were sealed with aluminium adhesive tape immediately after demoulding and placed in the climatic chamber at $23 \pm 3^{\circ} \mathrm{C}$. It was then that the first length (control length) measurement was carried out and periodically over 90 days. In order to determine the drying shrinkage value, after demoulding, the specimens were place in a climatic chamber at $23 \pm 3^{\circ} \mathrm{C}$ and $50 \% \pm 3 \%$ of 
RH and the initial length was measured. The length measurements were carried out periodically for 90 days.

Table 1. Mix proportions of Series 1 and Series 2 microconcrete mixtures. The values are given of $\mathrm{kg}$ of component $/ \mathrm{m}^{3}$ of concrete production.

\begin{tabular}{|c|c|c|c|c|c|c|c|c|}
\hline & Cement & $\begin{array}{l}\text { Fly } \\
\text { Ash }\end{array}$ & Sand & $\mathbf{A R}$ & $\begin{array}{r}\text { total } \\
\text { water }\end{array}$ & $\begin{array}{l}\text { Super } \\
(\%)^{*}\end{array}$ & $\begin{array}{c}\text { Efect. } \\
\text { w/c }\end{array}$ & D (mm) \\
\hline & \multicolumn{8}{|c|}{ SERIES 1} \\
\hline $\mathrm{C}-\mathrm{N}$ & 925.5 & - & 1111.5 & 0.00 & 268.9 & 0.70 & 0.27 & 250 \\
\hline C-MRA30 & 925.5 & - & 778.1 & 259.8 & 300.8 & 0.68 & 0.27 & 275 \\
\hline C-MRA50 & 925.5 & - & 555.8 & 433.0 & 322.1 & 0.68 & 0.27 & 275 \\
\hline C-CRA30 & 925.5 & - & 778.1 & 266.0 & 292.1 & 0.68 & 0.27 & 27.5 \\
\hline \multirow[t]{2}{*}{ C-CRA50** } & 925.5 & - & 555.8 & 443.3 & 307.6 & 0.68 & 0.27 & 30 \\
\hline & \multicolumn{8}{|c|}{ SERIES 2} \\
\hline C-FA-N & 462.7 & 317.6 & 1111.5 & 0.00 & 274.9 & 0.65 & 0.32 & 27.7 \\
\hline C-FA-MRA30 & 462.7 & 317.6 & 778.1 & 259.8 & 306.7 & 0.65 & 0.32 & 28.7 \\
\hline C-FA-MRA50 & 462.7 & 317.6 & 555.8 & 433.0 & 328.0 & 0.65 & 0.32 & 30 \\
\hline C-FA-CRA30 & 462.7 & 317.6 & 778.1 & 266.0 & 298,1 & 0.68 & 0.32 & 29 \\
\hline C-FA-CRA50** & 462.7 & 317.6 & 555.8 & 443.3 & 313.5 & 0.68 & 0.32 & 26.5 \\
\hline
\end{tabular}

*Admixture is the $\%$ with respect to cement weight ** C-CRA50-ABS or C-FA-CRA50-ABS: the absorption capacity of RCA was considered of 14\% determined following UNE-EN 1097-6

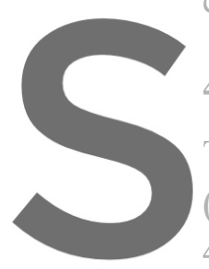
4.2 Compressive Strength
The compressive strength was detemined following UNE-EN 12390-3 specifications
(according to the dimensions and mechanical test procedure). Prismatic specimens of
40x40x160mm were producedfor all mixtures. They were dentoulded alter 24 hdurs of casting
and were exposed in a climatic chamber in identical conditions to those of the specimens

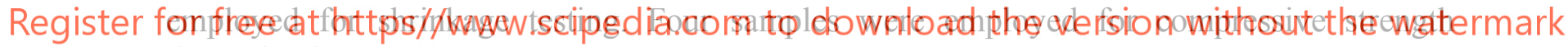
determination.

\section{Results}

\subsection{Autogenous (Sealed) Shrinkage and its Mechanical Properties}

\subsubsection{Shrinkage}

The sealed- autogenous shrinkage in hardened state of each mixture produced in series 1 and series 2 are illustrated in Figure 1. According to the results of the autogenous shrinkage in S1 samples, it was clear that the C-MRA50 mixture achieved the lowest shrinkage. The $50 \%$ of MRA, which had the highest absorption capacity, was efficient reducing initial shrinkage. The $\mathrm{C}-\mathrm{N}$ mixtures achieved the highest shrinkage during the first 2 days. In all probability this difference was higher during the first 24 hours after casting. In series 2, due to higher water and lower cement amount, the initial shrinkage values were lower than those in Series 1. After 28 days, the autogenous shrinkage of the C-MRA50 mixture was still found to be the lowest. However, the shrinkage caused by the hydration of the cementitious material was found to increase with time (see figure c) and d)). In all probability was due its to very high cementitious 
material. The mixtures produced employing $30 \%$ of MRA and CRA, and $50 \%$ of CRA were not able to release enough water in order to reduce the shrinkage value in series 1 . In series 2 , the RA worked more efficiently probably due to the slightly higher water amount employed in this series and the presence of FA.

\subsubsection{Compressive strength}

Figure 2 illustrates the compressive strength at 2 and 28 days of the recycled aggregate microconcretes produced in series 1 and series 2 with respect to those of the conventional microconcrete. The compressive strength values of C-N and C-FA-N at 2 days (2D) and 28 days (28D) are also described in figure 3. In series 1, all the Sc-microconcretes produced with RA achieved more than $95 \%$ of the compressive strength achieved by the C-N mixture after 2 days ( 1 day in mould and 1 day in the chamber). At 28 days, all the RA microconcrete obtained higher strength than that of the $\mathrm{C}-\mathrm{N}$ microconcrete. The C-MRA30 and C-CRA50 microconcretes achieved the highest strength. The internal curing capacity of the RA improved the compressive strength of the SC-microconcretes. However, the weak properties of the mortar present on the MRA reduced the strength of the SC-microconcrete when it was produced with $50 \%$ of MRA.

As expected the early strength value of SC-microconcretes was considerably reduced by using a high percentage of fly ash (Abdalhmid et al., 2019). The samples produced in series S2 achieved 50\% lower compressive strength than its corresponding sample in series S1 after 28 than that of C-AF-N achieved the same stren

In general, the SC-1m increase of strength from 2 to 28 days than tha
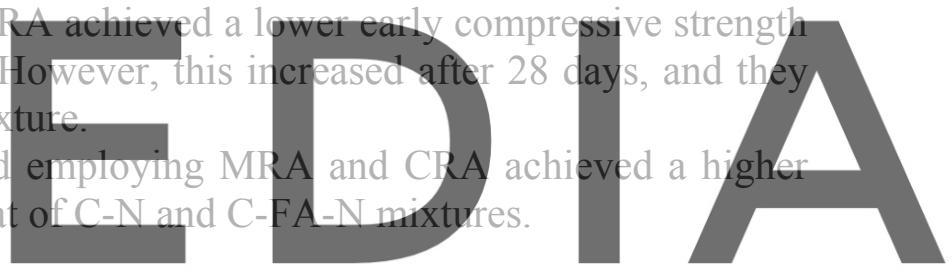

5.2 Drying Shrinkage and its Compressive Strength

Register for free at https//www.scipedia.com to download the version without the watermark 5.2.1 Drying shrinkage

Figure 3 a) and b) show the drying shrinkage values obtained by each mixture produced in series 1 and series 2, respectively, exposed to a climatic condition for 90days. In both series, the $\mathrm{C}-\mathrm{N}$ and $\mathrm{C}-\mathrm{FA}-\mathrm{N}$ mixtures obtained the lowest drying shrinkage value. While in series 1 (100\% of PC) the C-MRA50 and C-CRA50 mixtures achieved the highest shrinkage, in series 2 the SC-microconcrete produced with CRA achieved similar drying shrinkage to that of the CFA-N mixture. The FA reduced the rate of hydration and thus the drying shrinkage of the microconcrete containing FA was considerably lower than that of the S1 mixtures (Abdalhmid et al., 2019). 

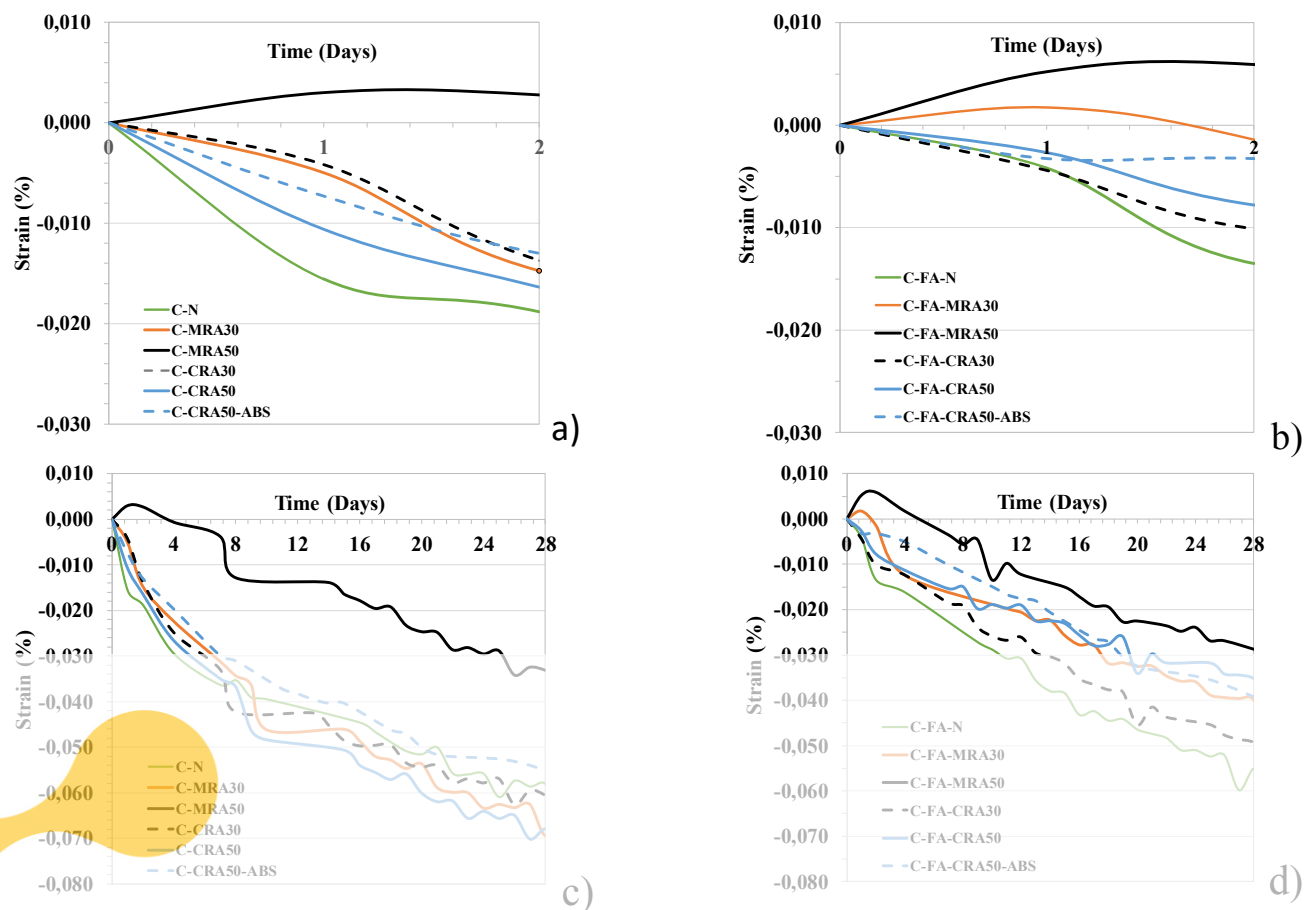

Figure 1. Autogenous (sealed) shrinkage values of Series 1 mixtures a) 2days, c) 28 days and Series 2 b) 2 days
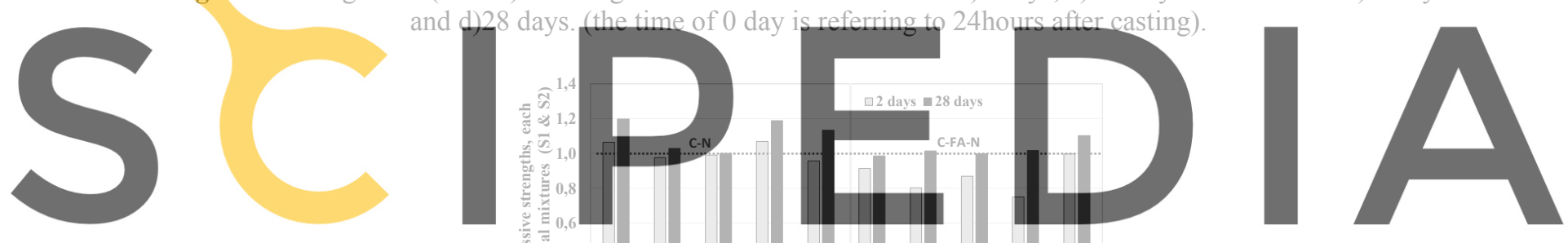

Register for free at https//www.

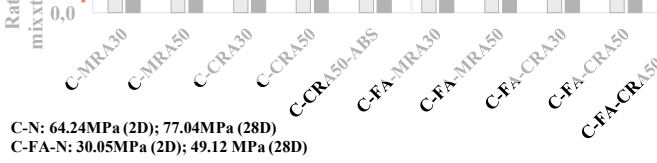

Figure 2. Ratio of compressive strength of recycled microconcretes with respect to conventional one at 2 days and 28 days after sealed condition at $23^{\circ} \mathrm{C}$.

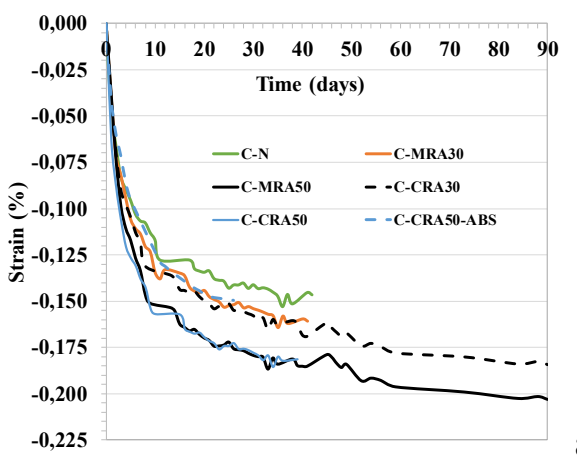

a)

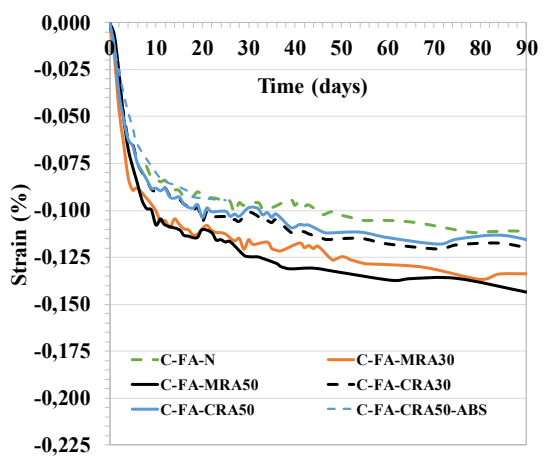

b)

Figure 3. Drying shrinkage of the samples produced at series 1 (a) and series 2 (b). 


\subsubsection{Compressive strength}

Figure 4 illustrates the compressive strength of SC-microconcretes produced with RA with respect to those of the conventional SC-microconcrete, series 1 and series 2, after 2 and 28 days. The compressive strength values of C-N and C-FA-N at 2 days (2D) and 28 days (28D) are also shown in figure 4. The SC-microconcretes produced in Series 1 achieved much higher strength than those produced in series 2 , due to the fast drying process, in all probability the high volume of FA was not hydrated.

In series 1, the C-CRA mixtures achieved higher compressive strength than that of the C-N mixture at 2 and 28 days. However, the increase of compressive strength, from 2 to 28 days, was lower in all RA mixture than that of $\mathrm{C}-\mathrm{N}$, with the exception of the C-CRA30 mixture.
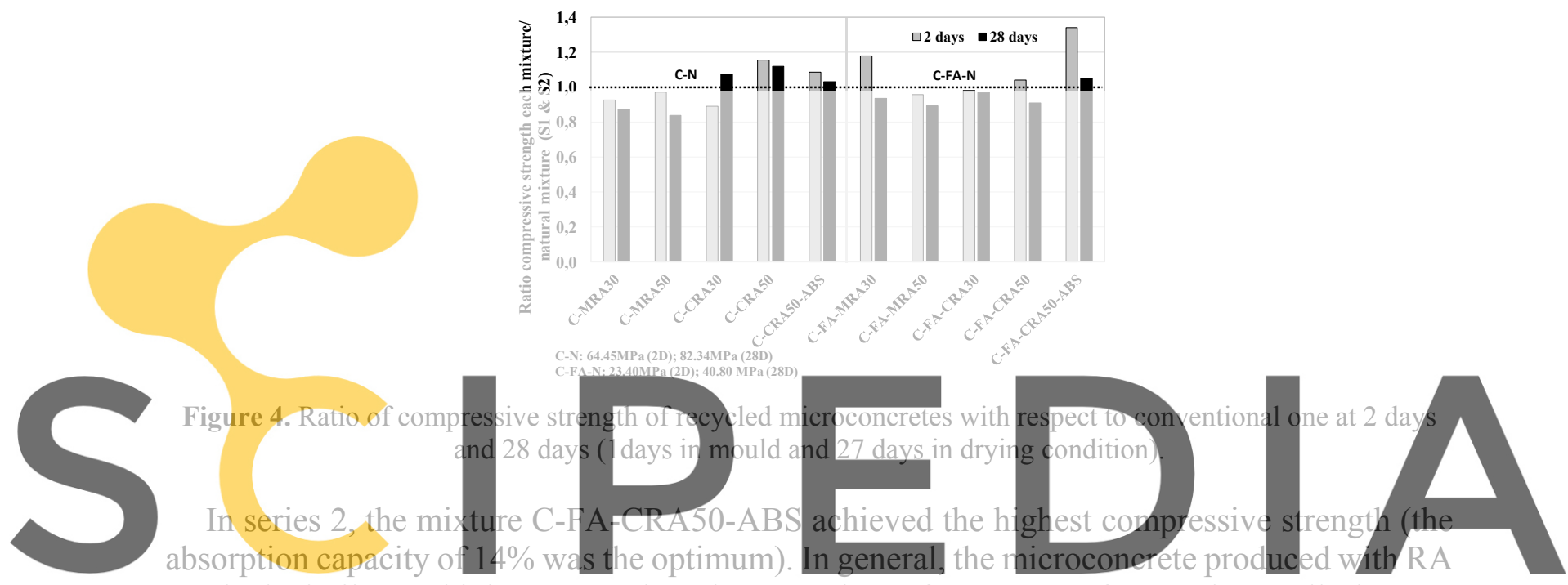

reached similar o higher strength values to that of C-FA-N after 2 days, all the RA

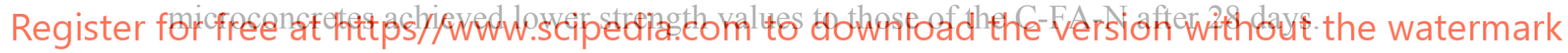

\section{Conclusions}

The following conclusions can be drawn based on the results presented above:

- The autogenous shrinkage was effectively reduced by employing the MRA and CRA aggregates in SC-microconcrete mixtures made with $100 \%$ of $\mathrm{PC}$, achieving also a higher compressive strength to the mixtures produced with NA. The C-MRA50 mixture achieved the lowest shrinkage value. However, due to the low mechanical properties of MRA aggregates, the C-MRA30 and C-CRA50 mixtures achieved a higher strength.

- The employment of 50\% FA as a binder caused a reduction of up to $40-50 \%$ of the autogenous shrinkage value. The compressive strength was also reduced when compared to the mixtures produced with $100 \%$ of PC. The use of RA in FA mixtures also produced a favourable effect on lowering of the shrinkage value and the increasing of the strength value with respect to those SC-microconcrete produced employing NA and FA after 28 days.

- Although the C-N achieved the lowest drying shrinkage, the mixtures with $30 \%$ of CRA and MRA were found to have similar values. In addition, the mixtures made with CRA achieved the highest compressive strength when $100 \%$ of PC was employed. 
- The employment of FA reduced the drying shrinkage as well as the compressive strength in up to $40-60 \%$ with respect to values obtained by mixtures produced with $100 \%$ of PC. The employment of the CRA aggregates improved the drying shrinkage and compressive strength of the C-FA-N mixture.

\section{Acknowledgements}

The authors want to thank the Ministry of Economy, Industry and Competitiveness (Ministerio de Economia, Industria y Competitividad, Spain) for the funding of the project BIA2017-85657-R (-HACCURACEM). The authors also want to thank the staff of the LATEM-UPC Laboratory for their support.

\section{ORCID}

Miren Etxeberria: https://orcid.org/0000-0003-2208-6207

\section{References}

Abdalhmid, J. M., Ashour, A. F., and Sheehan, T. (2019). Long-term drying shrinkage of self-compacting concrete: Experimental and analytical investigations. Construction and Building Materials, 202, 825-837. https://doi.org/10.1016/j.conbuildmat.2018.12.152

Al Saffar, D. M., Al Saad, A. J. K., and Tayeh, B. A. (2019). Effect of internal curing on behavior of high performance concrete: An overview. Case Studies in Construction Materials, 10, e00229. https://doi.org/10.1016/j.cscm.2019.e00229

Altoubat, S., Junaid, T. M., Leblouba, M., and Badran, D. (2017). Effectiveness of fly ash on the restrained shrinkage cracking resistance of self-compacting concrete. Cement and Concrete Composites, 79, 9-20. https://doi.org/10.1016/j.cemconcomp.2017.01.010

Ankush, G., Rajeey, C., and Workability Retention

Behera, M., Minocha, A shrinkage properties Building Materials,

Deschner, F., Winnefeld,
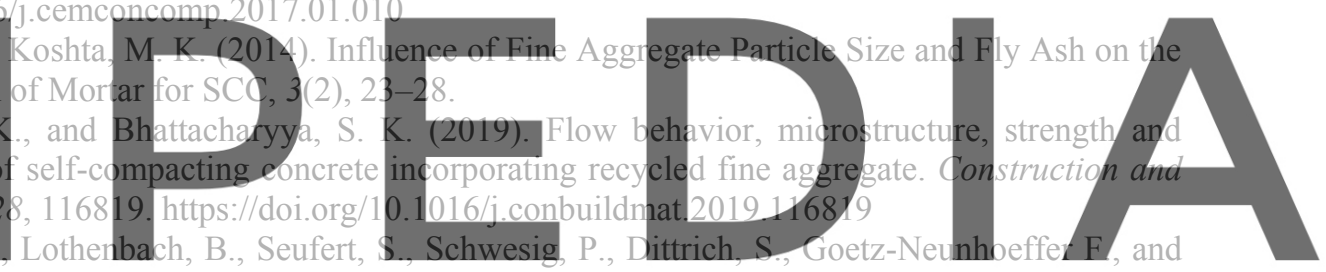
Neubauer, J. (2012). Hydration of Portland cement with high replacement by siliceous fly ash. Cement and

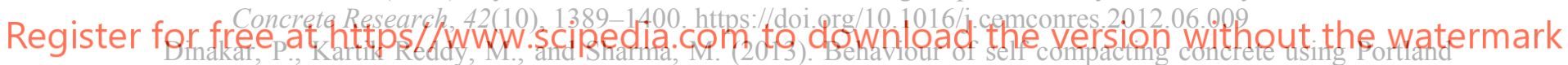
pozzolana cement with different levels of fly ash. Materials and Design, 46, 609-616. https://doi.org/10.1016/j.matdes.2012.11.015

Duran-Herrera, A., De-León-Esquivel, J., Bentz, D. P., and Valdez-Tamez, P. (2019). Self-compacting concretes using fly ash and fine limestone powder: Shrinkage and surface electrical resistivity of equivalent mortars. Construction and Building Materials, 199, 50-62. https://doi.org/10.1016/j.conbuildmat.2018.11.191

Etxeberria, Miren, and Gonzalez-Corominas, A. (2018). The assessment of ceramic and mixed recycled aggregates for high strength and low shrinkage concretes. Materials and Structures, 51(5), 1-21. https://doi.org/10.1617/s11527-018-1244-6

European Federation for Specialist Construction Chemicals and Concrete Systems (EFNARC). (2005). The European Guidelines for Self-Compacting Concrete Specification, Production and Use. (E. F. for S. C. C. and C. Systems, Ed.). Norfolk, UK. Retrieved from http://www.efnarc.org/pdf/SCCGuidelinesMay2005.pdf

Kristiawan, S. A., and Aditya, M. T. M. (2015). Effect of high volume fly ash on shrinkage of self-compacting concrete. Procedia Engineering, 125, 705-712. https://doi.org/10.1016/j.proeng.2015.11.110

Matos, P. R. de, Foiato, M., and Prudêncio, L. R. (2019). Ecological, fresh state and long-term mechanical properties of high-volume fly ash high-performance self-compacting concrete. Construction and Building Materials, 203, 282-293. https://doi.org/10.1016/j.conbuildmat.2019.01.074

Suzuki, M., Seddik Meddah, M., and Sato, R. (2009). Use of porous ceramic waste aggregates for internal curing of high-performance concrete. Cement and Concrete Research, 39(5), 373-381. https://doi.org/10.1016/j.cemconres.2009.01.007 